\title{
A Systematic Review of Interventions to Improve Healthcare Experiences and Access in Autism
}

\author{
Chloe Walsh ${ }^{1,2} \cdot$ Paul O'Connor $^{1,2} \cdot$ Ellen Walsh $^{2} \cdot$ Sinéad Lydon ${ }^{2,3}$ (i)
}

Received: 24 September 2020 / Accepted: 25 June 2021

(c) The Author(s) 2021

\begin{abstract}
Autistic individuals report barriers to accessing and receiving healthcare, and experience increased morbidity and mortality. This systematic review synthesizes 31 research studies evaluating interventions implemented to improve the healthcare experiences and/or access of autistic persons. Interventions were most commonly patient-focused (58.1\%), focused on supporting the autistic individual to engage with, tolerate, or anticipate medical procedures, care, or settings. Fewer studies were provider-focused (48.4\%) or organization-focused (6.5\%). Interventions were typically evaluated using measures of reactions $(45.2 \%)$ or behavior $(48.4 \%)$, and outcomes were predominantly positive (80.6\%). Further research is imperative and should look to how providers and organizations must change. Future research must be inclusive of the autistic community, must measure what matters, and must offer complete detail on interventions implemented.
\end{abstract}

Keywords Autism $\cdot$ Autistic $\cdot$ Healthcare $\cdot$ Health equity $\cdot$ Quality of care $\cdot$ Review

\section{Introduction}

Autism is a neurodevelopmental condition characterized by differences in social and communication skills, along with the presence of repetitive and/or restricted behaviors and interests (American Psychiatric Association, 2013). Autistic ${ }^{1}$ individuals are more likely to experience illness or disease than others. Poor health is estimated to be more than five times more likely among autistic adults than among neurotypical adults (Rydzewska et al., 2019). Autistic individuals have a higher likelihood of experiencing a variety of medical conditions such as autoimmune disease, cardiovascular diseases, neurological conditions, and gastrointestinal disorders (Croen et al., 2015). A number of studies, analyzing data from different countries, have also evidenced substantially increased mortality, in some cases up to twice as high, among autistic persons (Hirvikoski et al., 2016;

Sinéad Lydon

sinead.lydon@nuigalway.ie

1 Department of General Practice, School of Medicine, National University of Ireland Galway, Galway, Ireland

2 Irish Centre for Applied Patient Safety and Simulation, National University of Ireland Galway, Galway, Ireland

3 School of Medicine, National University of Ireland Galway, Galway, Ireland
Hwang et al., 2019; Mouridsen et al., 2008; Shavelle et al., 2001). This means autistic individuals are more likely to die than their peers over a period of time. Further, compared to neurotypical controls, autistic individuals have a greater number of unmet healthcare needs (Nicolaidis et al., 2013), receive less preventative care (Nicolaidis et al., 2013), report more frequent use of emergency care (Nicolaidis et al., 2013; Tregnago \& Cheak-Zamora, 2012), and have a lower healthrelated quality of life (Khanna et al., 2014; Kuhlthau et al., 2010). However, poor health is not an inevitable consequence of autism but instead reflects important health inequities experienced by autistic individuals that exist internationally (Bishop-Fitzpatrick \& Kind, 2017; Tregnago \& Cheak-Zamora, 2012).

Health inequities are defined as "unjust and avoidable differences in healthcare access, quality, and outcomes" (Scott \& Rawal, 2018, p.1; Whitehead, 1991). Potential determinants of, or contributors to, the health inequities observed among persons with intellectual disabilities are

${ }^{1}$ We have deliberately opted to use identity-first language (i.e., autistic individual) rather than person-first language (i.e., individual with autism) in this manuscript. The appropriate use of language around autism is recognized as a complex issue (Shakes \& Cashin, 2019). However, we have made this decision as, in recent years, autistic individuals have expressed a strong preference for the use of identity-first language (Kenny et al., 2016; Robison, 2019) and the use of personfirst language has been suggested to perpetuate or sustain stigma around disability (Gernsbacher, 2017). 
well-delineated and are suggested to include increased experience of undesirable social determinants of health (e.g., poverty and unemployment), communication problems and health illiteracy, poor health-related behaviors, and poor access to, and quality of, healthcare (Emerson, 2011; Emerson \& Baines, 2011). It is likely that such factors also play a role in perpetuating health inequities for autistic individuals (Brugha et al., 2016; Mason et al., 2019; Muskat et al., 2015; Walsh et al., 2020a) making this a complex issue. For instance, research shows that autistic people are more likely to be less educated, unmarried, and more socially deprived than the general population (Brugha et al., 2016). Similarly, it is well-recognized that autistic individuals experience issues in accessing and receiving high quality healthcare (Mason et al., 2019; Muskat et al., 2015; Walsh et al., 2020a).

Barriers to healthcare access can occur at the level of the patient, the healthcare provider, and the healthcare system (Walsh et al., 2020a). Key barriers to healthcare access occurring at the level of the patient can include sensory sensitivity which makes it difficult for the individual to experience novel or stimulating settings or to tolerate physical exams or investigations (Mason et al., 2019; Walsh et al., 2020a); communication difficulties which complicate identification of pain or symptoms and engagement with healthcare providers regarding investigations or treatments (Mason et al., 2019; Walsh et al., 2020a), and; challenging behaviors (e.g., self-injurious behavior; aggression; stereotypy) which can cause the discontinuation of medical procedures, result in the use of physical and/or chemical restraint (e.g., Kamat et al., 2018), or make caregivers less likely to attend for medical appointments (Walsh et al., 2020a). Barriers to healthcare access occurring at the level of the healthcare provider include a lack of provider knowledge or skill relating to autism which impedes their ability to adapt care for autistic patients or to understand their experiences or needs (Mason et al., 2019; Walsh et al., 2020a); inflexibility of healthcare providers or a lack of willingness to make accommodations or change their behavior to facilitate the autistic patient (Mason et al., 2019; Walsh et al., 2020a), and; healthcare providers ignoring, or not taking seriously, the concerns or expertise of the autistic patient or their caregiver (Mason et al., 2019; Walsh et al., 2020a). Barriers also occur at the level of the organization or health system and these include a lack of continuity of care or collaboration between the different healthcare providers or services involved in the management of the autistic patient's care (Walsh et al., 2020a); time or resource constraints which impede the delivery of high quality care to the autistic patient (Walsh et al., 2020a), and; financial and/or insurance issues which can preclude autistic individuals from accessing required care or making use of preventative care services (Walsh et al., 2020a). Systematic reviews (Mason et al., 2019; Walsh et al., 2020a) of barriers to healthcare access showcase the range of barriers that can impede care and emphasize the complexity of the challenge of improving healthcare access and experiences for autistic persons.

It has been mandated in the UK that public services adjust their practices to accommodate autistic people (Department of Health, 2010). Further, the development of autismfriendly healthcare services is a recognized research priority of the autistic community (Warner et al., 2019). There is an increasing focus internationally on making environments and processes "autism-friendly" which involves identifying the challenges or difficulties that autistic individuals may experience when engaging with them and making adaptations to facilitate the participation of autistic individuals (e.g., addressing sensory sensitivity by reducing noise levels or removing fluorescent light to make the environment less stimulating; Nguyễn, 2009). However, although the barriers to healthcare access have been well-considered and shown to exist across many countries (Mason et al., 2019; Muskat et al., 2015; Walsh et al., 2020a), there is a lack of guidance on how to improve the care of autistic patients. To date, suggestions for improving healthcare have been described (Barber, 2017; Bellando et al., 2016; Nicolaidis et al., 2014; Souders et al., 2002; Venkat et al., 2012; Walsh et al., 2020a) but there has been no attempt to synthesize interventional research in this area and to examine the types of interventions which have been employed and their outcomes. Understanding what type of interventions have been trialed to date, and their effects, is important for informing both research and practice in this area. Accordingly, the purpose of this systematic review was to synthesize the research evaluating interventions to improve the healthcare experiences and/or access of autistic persons.

\section{Method}

\section{Study Design}

This systematic review was conducted, and is reported, in accordance with the Preferred Reporting Items for Systematic Reviews and Meta-analysis (PRISMA) guidelines (Moher et al., 2009). The protocol was registered in the International Prospective Register of Systematic Reviews (PROSPERO; CRD42020163200).

\section{Search Strategy}

A systematic search of five electronic databases was completed in January 2020. The databases searched were Medline, CINAHL, Web of Science, Psychology and Behavioral Sciences Collection, and PsycInfo. The search 
protocol, developed with the assistance of a research librarian, included Medical Subject Headings (MeSH) search terms along with other keywords that related to autism, healthcare, and interventions. The search strategy for Medline is presented in Supplemental Digital Content 1 and was adapted as necessary for the other databases. Searches were limited to the English language but no restriction was placed upon year of publication.

It is well-recognized that the exclusion of grey literature (i.e., materials not published in peer-reviewed journals) can lead to the overestimation of intervention effects within systematic reviews (Hopewell et al., 2007). Accordingly, grey literature searches were undertaken in November 2019 to identify unpublished materials suitable for inclusion in this review. Searches were conducted across: (1) Google (first 100 returns; location set to UK); (2) Google Scholar (first 100 returns; location set to UK); (3) Ethos (e-theses online service; all returns examined), and (4) OpenGrey (System for Information on Grey Literature in Europe; all returns examined). Across each of these databases, the keyword "autism" was entered along with one of the following terms: health; healthcare; hospital; general practice; doctor; physician, and nurse.

In order to identify additional relevant studies, the reference lists of a number of related reviews (Koski et al., 2016; Kupzyk \& Allen, 2019; Lydon et al., 2015; McCormack et al., 2019) were screened along with the reference lists of all studies determined to be suitable for inclusion following the electronic searches.

\section{Study Selection}

\section{Inclusion and Exclusion Criteria}

In order to be included in this review, studies were required to (a) be written in the English language; (b) describe the implementation and evaluation of an intervention to improve healthcare access or care experiences for autistic persons in relation to physical healthcare specifically (defined as any medical care related to the physical wellbeing of the participants; Walsh et al., 2020a), and (c) use an established research design. The interventions described could include autistic individuals or their caregivers, healthcare staff, or could target change or improvement within organizations or health systems.

Studies were excluded if they involved the development or consideration of relevant interventions but did not evaluate these (e.g., Carter et al., 2017). In addition, studies were excluded if their focus was not specific to autism and/or it was not possible to extract data pertaining to the outcomes of the intervention for autistic participants or their caregivers (e.g., Drake et al., 2012). Other reasons for exclusion included the following: implementation of an intervention with a focus on improving healthcare providers' diagnostic or screening capabilities (e.g., Bauer et al., 2015); interventions implemented in mental health or dental settings (e.g., Kuriakose et al., 2018); case reports or studies or multiple case studies reported together (e.g., Edwards \& Northway, 2011); and no original, empirical data provided (e.g., Ailey et al., 2017). In some cases, multiple exclusion criteria were relevant to an individual study.

\section{Screening}

Titles and abstracts of all records returned during the electronic searches were screened by one author. If a study appeared relevant, or it was not possible to determine whether it met the inclusion and exclusion criteria, the full text was accessed. Full text review was completed by the full research team in tandem, and decisions regarding inclusion or exclusion were documented (see Supplemental Digital Content 2).

\section{Data Extraction and Synthesis}

Two authors independently completed data extraction with any disagreements resolved through discussion until consensus was achieved. Data were extracted on country, intervention setting(s), participant(s), research approach, intervention characteristics, evaluation measures, and outcomes.

As the included papers were diverse with regard to research design, and interventions implemented, it was necessary to develop and apply codes to facilitate data synthesis. Throughout the coding process, researchers were careful to ensure that the context and meaning of data was retained in spite of the application of codes (Sandelowski et al., 2012). Coding was completed by the research team together following completing of initial data extraction, discussing each study in detail prior to developing and/or selecting the appropriate code(s). The importance of dialogue between researchers during coding has been outlined previously (Graneheim \& Lundman, 2004). Table 1 presents a complete summary of codes applied to synthesize data on participants (e.g., autistic children/adults and healthcare providers), setting (e.g., educational setting for autistic children/adults and primary care), evaluation measures (e.g., measures of reactions and measures of behavior), the intervention implemented (e.g., patient-focused and provider-focused), and the outcomes of the intervention (e.g., positive and mixed). With regard to evaluation measures employed, Kirkpatrick's evaluation hierarchy (Kirkpatrick, 1967) was used to categorize the level of evaluation completed as has been done in other systematic reviews previously (Hammick et al., 2010; O'Dea et al., 2014). Further, outcome data within each paper were coded using a grading system of positive/mixed/negative/ 
Table 1 Codes applied to summarize data relating to participants, settings, the type of evaluation measures applied, the nature of the intervention, and the outcomes achieved

\begin{tabular}{|c|c|c|c|c|}
\hline Participants & Setting & $\begin{array}{c}\text { Type of Evaluation Measures } \\
\text { Employed }\end{array}$ & The Nature of the Intervention & Outcomes Achieved \\
\hline $\begin{array}{l}\text { Autistic children/adults } \\
\text { Any autistic participant(s), } \\
\text { regardless of age or any } \\
\text { indicated co-occurring } \\
\text { diagnoses or conditions. } \\
\text {---- } \\
\text { Healthcare providers } \\
\text { Any participant(s) involved in } \\
\text { the delivery of medical care to } \\
\text { patients, including physicians, } \\
\text { nurses, emergency medical } \\
\text { services personnel and others. } \\
\text {------- } \\
\text { Caregivers of autistic } \\
\text { children/adults } \\
\text { Any participant(s) identified } \\
\text { as caregivers to autistic } \\
\text { individuals receive healthcare } \\
\text { services, to include family } \\
\text { members or those employed } \\
\text { as support workers for autistic } \\
\text { individuals. } \\
\text {---------------- } \\
\text { Healthcare administrators } \\
\text { Any participant(s) involved in } \\
\text { the organisation or } \\
\text { management of healthcare } \\
\text { services or settings. } \\
\text {------ } \\
\text { Health Profession Students } \\
\text { Any participant(s) completing } \\
\text { a health-profession related } \\
\text { educational degree, to include } \\
\text { medical, nursing and other } \\
\text { health sciences students. }\end{array}$ & 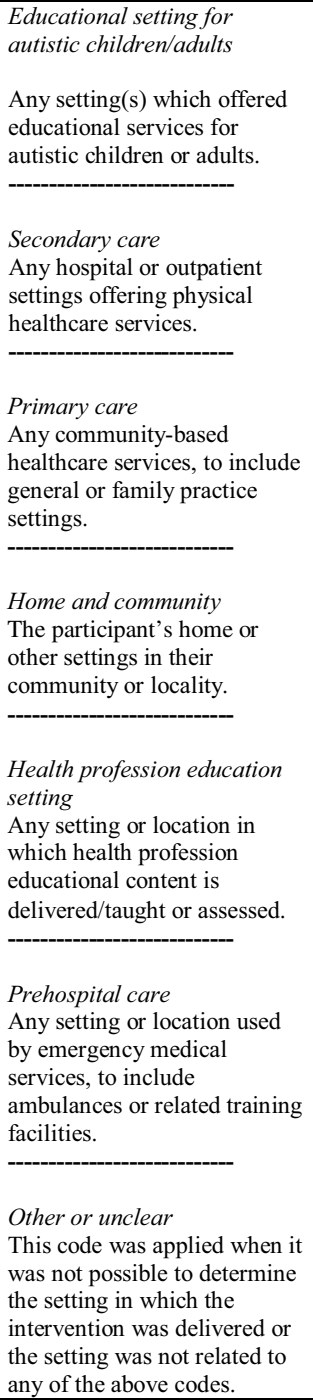 & 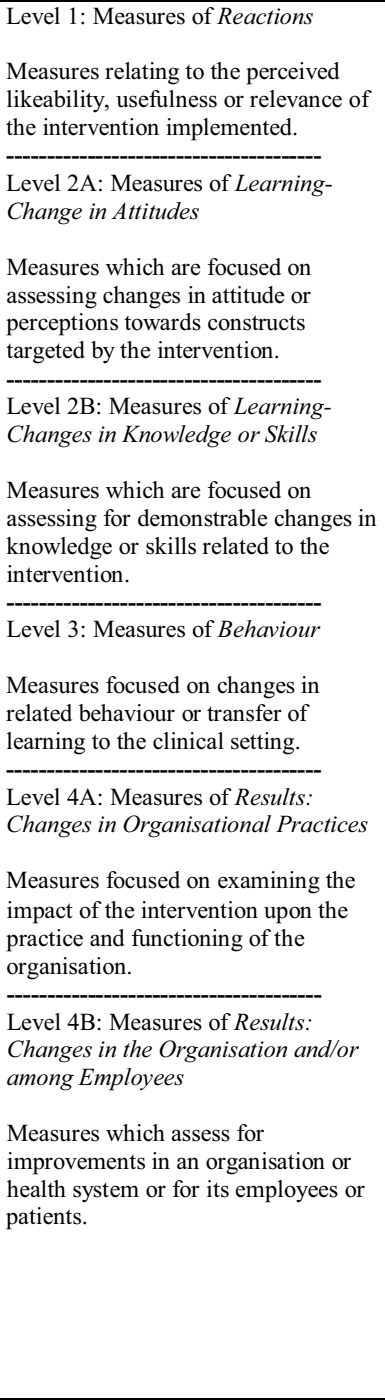 & $\begin{array}{l}\text { Interventions which are patient- } \\
\text { focused } \\
\text { Interventions that are focused on } \\
\text { supporting the autistic individual to } \\
\text { engage with, tolerate, or anticipate, } \\
\text { medical procedures, medical care or } \\
\text { healthcare settings. } \\
\text { - } \\
\text { Interventions which are provider- } \\
\text { focused } \\
\text { Interventions which are focused on } \\
\text { equipping healthcare providers with } \\
\text { the knowledge and skills required to } \\
\text { effectively support and care for } \\
\text { autistic patients. } \\
\text {------------------------------ } \\
\text { Interventions which are } \\
\text { organisation-focused } \\
\text { Interventions focused on altering the } \\
\text { physical environment or } \\
\text { organisation in ways that create a } \\
\text { more inclusive and supportive } \\
\text { environment for autistic individuals. }\end{array}$ & 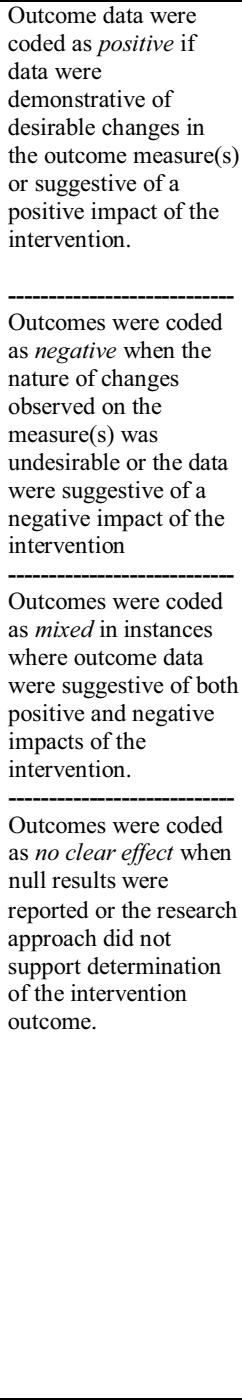 \\
\hline
\end{tabular}

no clear effect, a similar process to that employed in other systematic reviews (e.g., McCormack et al., 2019) previously. Multiple codes were applied if required to capture the data presented.

\section{Methodological Rigor}

Methodological rigor was assessed by two researchers working in tandem and using the Quality Assessment Tool for Studies with Diverse Designs (QATSDD; Sirriyeh et al., 2012) which allows for the appraisal of studies using quantitative, qualitative, or mixed methods approaches. This 16-item tool has been widely applied in systematic reviews pertaining to autism and/or health services research (Ayres et al., 2018; McCormack et al., 2019; O’Dowd et al., 2019;
Walsh et al., 2020a). Items are rated on a four-point scale (0-3), with a higher score indicating greater rigor.

\section{Results}

Figure 1 presents a PRISMA flow diagram depicting study selection. Titles and abstracts were examined for more than 3,800 records with full texts considered for 191 papers and 30 papers (Birkan et al., 2011; Broder-Fingert et al., 2016; Carbone et al., 2016; Cavalari et al., 2013; Chebuhar et al., 2013; Clark et al., 2016; Cox et al., 2017; Cuvo et al., 2010; Davit et al., 2011; Ellis et al., 2006; Ghuman et al., 2004; Giarelli et al., 2012; Gillis et al., 2009; Golnik et al., 2012; Havercamp et al., 2016; Iannuzzi et al., 2019; Lucarelli et al., 2018; Mazurek et al., 2017; Mazurek et al., 2019; 
McGonigle et al., 2014; McIntosh et al., 2015; Mills, 2017; Nicolaidis et al., 2016; Riosa et al., 2017; Riviere et al., 2011; Schiff et al., 2011; Shabani \& Fisher, 2006; Swartz et al., 2017; Whippey et al., 2019; Wolff \& Symons, 2013), describing 31 studies, ultimately included. Almost all studies (96.8\%) were peer-reviewed with the exception of one study (Mills, 2017) which comprised a student thesis. Of the 31 studies included, more than $70 \%$ were conducted in the USA and $16 \%$ conducted in Canada. Studies conducted outside of North America were much fewer in number $(<15 \%$ of included studies). Table 2 provides a summary of the characteristics of included studies with a study-by-study summary available in Supplemental Digital Content 3.

\section{Participants}

As shown in Table 2, participants in the studies were most commonly autistic children or adults ( $61.3 \%$ of studies), followed by healthcare providers ( $29 \%$ of studies). The participation of caregivers of autistic children or adults, healthcare administrators, and health profession students was less frequent (all $<15 \%$ of studies) across the studies reviewed.

\section{Setting}

Studies were most commonly conducted in primary care, secondary care, or educational settings (all in $22.6 \%$ of studies) that served autistic children or adults (see Table 2). Studies conducted in participants' homes or the community, health profession education settings, prehospital care, or elsewhere were less frequent.

\section{Research Approach}

As outlined in Table 2, studies were predominantly quantitative only, typically using groups research designs (51.6\%; e.g., pretest-posttest design; quasi-randomized controlled trial) though single-subject research designs (e.g., changing criterion design; multiple baseline across participants design) were also common (32.3\%). Five studies (16.1\%) used a mixed methods research approach, collecting both qualitative and quantitative data as part of the intervention evaluation conducted.

\section{Level of Evaluation}

Full detail on the evaluations of interventions within studies is provided in Supplemental Digital Content 3 while Table 3 provides a summary of evaluation across the included studies, examples of evaluations conducted, and associated outcomes. Studies most commonly assessed behavior $(54.8 \%$ of studies; e.g., compliance with components of a medical exam) followed by the assessment of reactions $(45.2 \%$; e.g., caregiver satisfaction with care) and then changes in attitudes (29\%; e.g., confidence working with autistic patients). As can be seen in Table 3, for each Kirkpatrick 1967, level of evaluation, the majority of outcomes observed were positive.

\section{Outcomes}

In total, $80.6 \%(n=25)$ of studies demonstrated positive outcomes. A further four studies showed positive outcomes on some measures and either no clear effects $(n=3 ; 9.7 \%)$ or mixed effects $(n=1 ; 3.2 \%)$. The two final studies reported outcome data that was classified as no clear effects.

\section{Nature of the Intervention}

For complete information on interventions delivered, please see Supplemental Digital Content 3. Table 4 provides an overview of the types of interventions reported, along with examples and information on outcomes. A majority of studies were patient-focused $(58.1 \%)$ with the intervention predicated on supporting the autistic patient to engage with, tolerate, or anticipate medical procedures, care, or settings. Targets in these studies varied but included teaching cooperation with injections (Birkan et al., 2011) and improving communication with autistic patients during medical exams (Mills, 2017). These interventions typically took the form of a behavioral intervention (72.2\%). Outcomes of patient-focused interventions were predominantly positive (88.9\% showing positive outcomes only).

Interventions were also commonly provider-focused (48.4\%), or intended to equip healthcare providers with the knowledge and skills required to effectively support and care for autistic patients. Targets within studies varied but it was most common for studies to seek to improve staff knowledge of autism or attitudes towards autistic patients. These interventions were typically educational interventions (66.6\%), though a small number of studies did describe care plans or quality improvement deemed to be provider-focused. Outcomes of provider-focused interventions were typically positive ( $66.6 \%$ of studies showing positive outcomes only).

Only two studies (6.5\%) reported the use of interventions classified as organization-focused, and which dealt with altering the physical environment or organization in ways that created a more inclusive and supportive environment for autistic individuals. Both studies described the use of care plans for autistic patients, with one study documenting positive outcomes only (Whippey et al., 2019) and the other showing a positive effect on two outcome measures and no clear effect on a third (Swartz et al., 2017). 
Fig. 1 PRISMA flow diagram depicting study selection

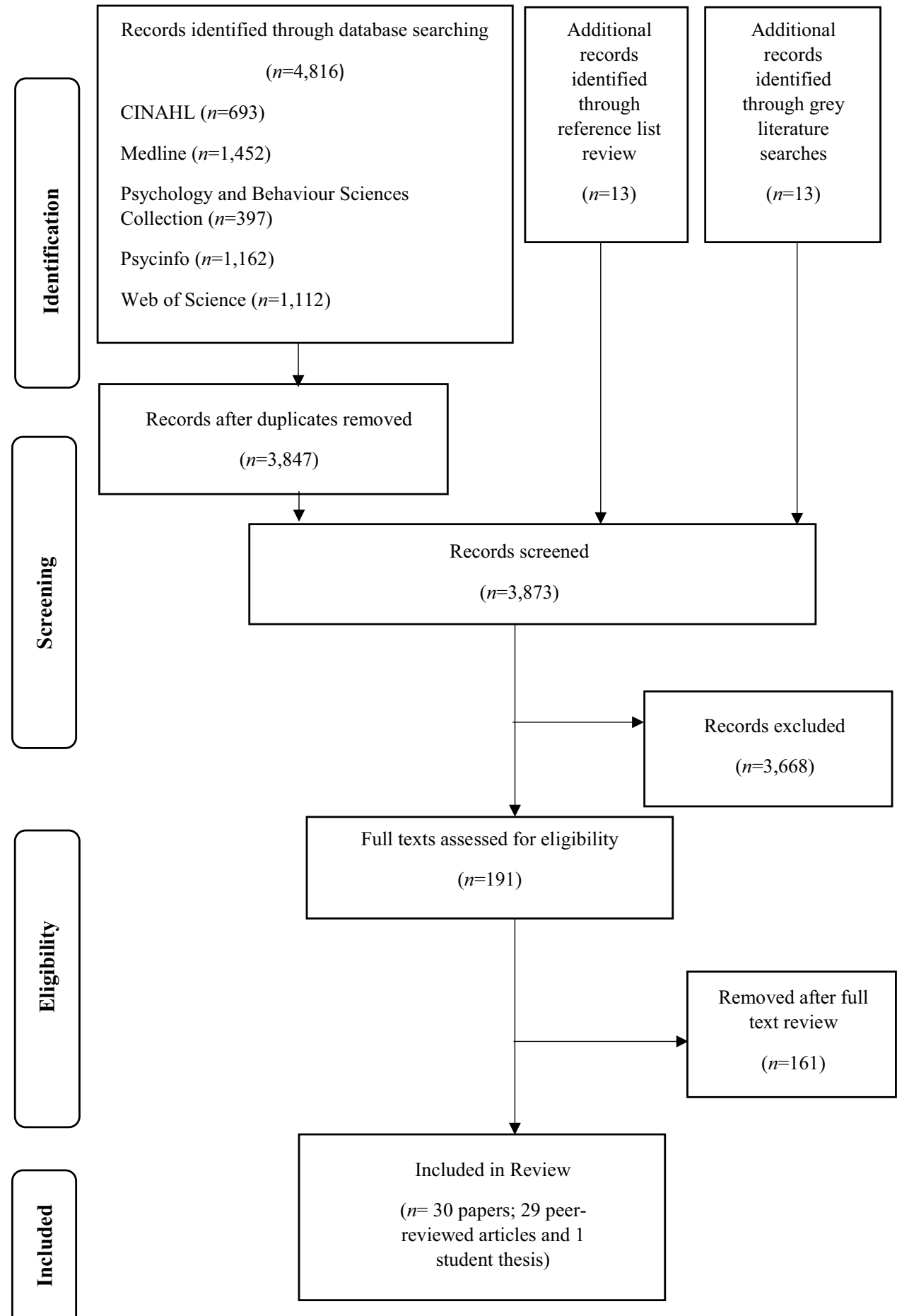

performed most poorly on items appraising consideration of sample size, justification of analyses, and user involvement in design.

\section{Comparison by Research Design}

Of the 31 studies included, 11 utilized a single-subject research design (35.5\%; e.g., changing criterion design; 
Table 2 Summary of the characteristics of included studies ( $n=31$ studies)

\begin{tabular}{lll}
\hline Summary & & $N$ of studies (\%)* \\
\hline Country & USA & $23(74.2 \%)$ \\
& Canada & $5(16.1 \%)$ \\
UK & $2(6.5 \%)$ \\
Participants & Other (i.e., Turkey, France) & $2(6.5 \%)$ \\
& Autistic children/adults & $19(61.3 \%)$ \\
& Healthcare providers & $9(29 \%)$ \\
& Caregivers of autistic children/adults & $4(12.9 \%)$ \\
Setting & Healthcare administrators & $3(9.7 \%)$ \\
& Health profession students & $2(6.5 \%)$ \\
& Educational setting for autistic children/adults & $7(22.6 \%)$ \\
& Secondary care & $7(22.6 \%)$ \\
& Primary care & $7(22.6 \%)$ \\
& Home and community & $5(16.1 \%)$ \\
& Health profession education setting & $4(12.9 \%)$ \\
Research approach & Prehospital care & $1(3.2 \%)$ \\
& Other or unclear setting & $4(12.9 \%)$ \\
& Quantitative-groups research & $16(51.6 \%)$ \\
& Quantitative-single-subject research & $10(32.3 \%)$ \\
& Mixed methods & $5(16.1 \%)$ \\
\hline
\end{tabular}

Note. Percentages do not total to $100 \%$ as some studies fell within more than one of the categories presented reversal design) and 21 utilized some form of groups design (67.7\%; e.g., randomized controlled pilot trial study). Table 5 presents a comparison of the level of evaluation, nature of intervention, outcomes, and methodological rigor by research design. As can be seen, there appeared to be less variability within the methods and outcomes of studies utilizing single-subject research designs.

\section{Discussion}

Morbidity and mortality are substantially increased among autistic individuals internationally. Relatedly, autistic individuals experience issues in accessing and receiving high quality healthcare that are not experienced by neurotypical individuals (Mason et al., 2019; Muskat et al., 2015; Walsh et al., 2020a). There is therefore a need, and in some countries a legal requirement, to develop and implement interventions that can improve the healthcare experience or access of autistic persons. Accordingly, the current systematic review offers a synthesis of research on interventions to improve healthcare experiences and/or access for autistic persons. Key findings include the small body of research describing evaluations of relevant interventions, the predominant focus on changing the behavior of the patient with comparatively little work focused on changing healthcare provider behavior and/or healthcare organizations and systems, and relatively weak forms of outcome measurement.
Although many papers exist that provide recommendations for providing healthcare to autistic individuals (Barber, 2017; Bellando et al., 2016; Nicolaidis et al., 2014; Souders et al., 2002; Venkat et al., 2012), a much smaller body of literature ( $n=30$ papers) has evaluated interventions to improve access to, or experiences of, healthcare for autistic persons. Of the studies reviewed, only $13 \%$ were conducted outside of North America and just under half (48.3\%) took place in a healthcare setting. A recent workshop (Warner et al., 2019) that brought together autistic people, their relatives, clinicians, healthcare managers, and others identified the development of autism-friendly healthcare services as a research priority. While it is encouraging that a majority of studies reviewed herein $(80.6 \%)$ demonstrated positive outcomes of interventions, the autistic community is heterogeneous (Nicolaidis et al., 2014) and additional research will be required to explore, and establish, a variety of evidence-based practices suitable for facilitating care of autistic individuals of all ages, and across all health specialties and settings. This is particularly true given that none of the included studies employed a full randomized controlled trial design (two studies employed randomization but were described as pilot studies) which continues to constitute the "gold standard" for interventional research and to afford the most trustworthy evidence on effectiveness (Bothwell et al., 2016; Hariton \& Locascio, 2018). However, research has now effectively delineated the barriers to healthcare access (Calleja et al., 2020; Mason et al., 2019; Walsh et al., 2020a), 


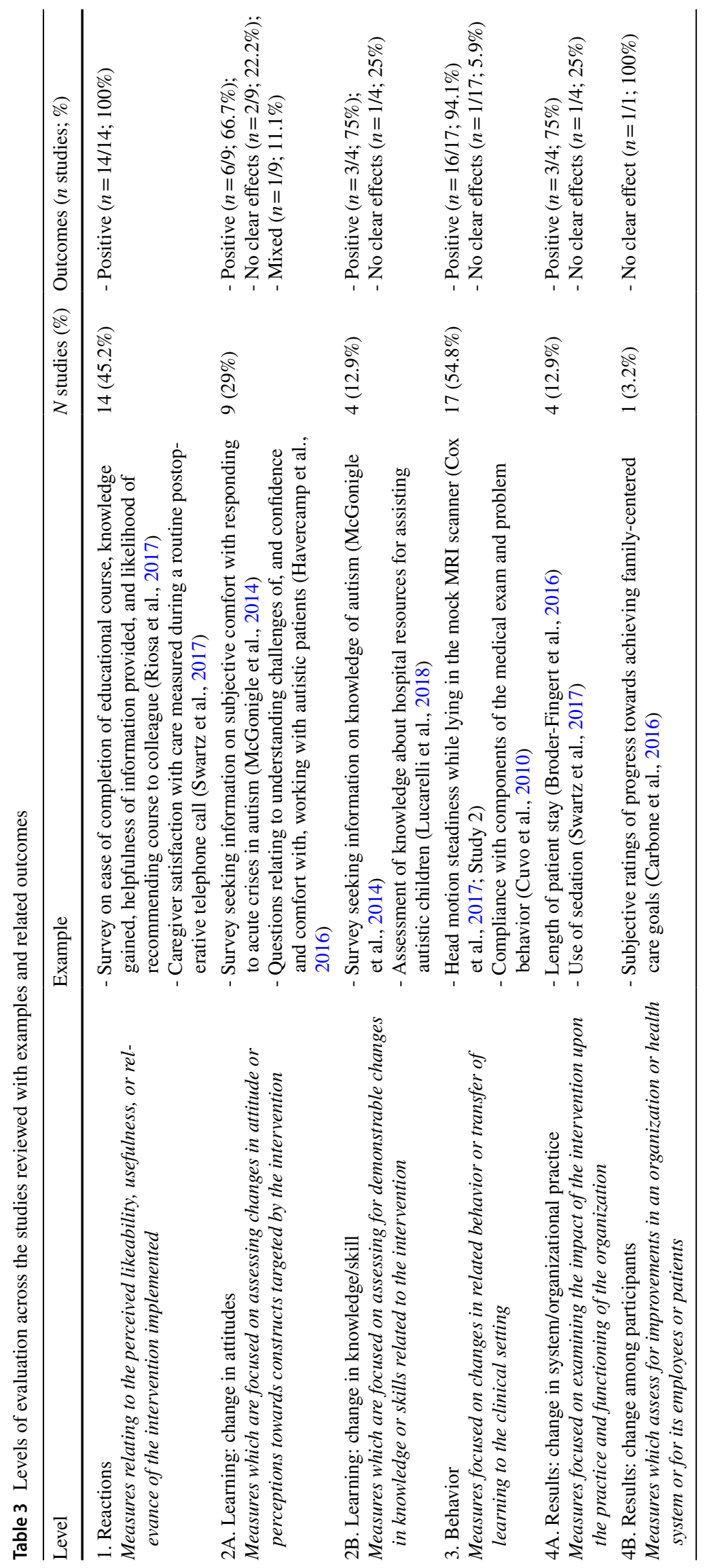


Table 4 Types of interventions reported across the included studies, with examples and related outcomes

\begin{tabular}{ll}
\hline Nature of intervention; $n(\%)$ & Type and examples \\
\hline Patient-focused; $18(58.1 \%)$ & Behavioral intervention $(n=13 / 18 ; 72.2 \%)$ - e.g., behavioral \\
& intervention drawn from science of Applied Behavior Analy- \\
& sis which comprised of skills teaching, a token economy, and \\
& reinforcement to teach cooperation with injections (Birkan et al., \\
& $2011)$
\end{tabular}

Picture schedule $(n=2 / 18 ; 11.1 \%)$ - e.g., the use of pictures schedules to inform autistic patients of what is expected during a hospital visit (Chebuhar et al., 2013)

Care plan $(n=2 / 18 ; 11.1 \%)$ - e.g., use of the Autism Healthcare - Positive $(1 / 2 ; 50 \%)$ Accommodation Tool which allows patients to create a personalized accommodations report for their primary care provider (Nicolaidis et al., 2016)

Quality improvement $(n=1 / 18 ; 5.6 \%)$ - e.g., autism-specific medical home intervention that utilized a QI approach and included accomplishments such as an autism care plan, tools to improve appointments, coordination with outside resources, and longer duration appointments (Golnik et al., 2012)

Provider-focused; $15(48.4 \%)$

Educational intervention $(n=10 / 15 ; 66.6 \%)$ - e.g., an online training module for healthcare professionals that covered an introduction to autism and recommended proactive and reactive strategies for caring for autistic pediatric patients (Riosa et al., 2017)

Care plan $(n=4 / 15 ; 26.7 \%)$ - e.g., an autism specific care plan was developed and addressed: expressive and receptive communication, social and pragmatic concerns, and safety. It was completed by patient and uploaded to the patient's electronic record (Broder-Fingert et al., 2016)

Quality improvement $(n=1 / 15 ; 6.7 \%)$ - e.g., teams developed plans for change (e.g., improving chronic care management of autistic children) and a timeframe. To support implementation of plans, there were monthly conference call on autism-related topics and two site visits from a QI specialist (Carbone et al., 2016) Organization-focused; $2(6.5 \%) \quad \begin{array}{r}\text { Care plan }(n=2 / 2 ; 100 \%) \\ \text { perative plan for autistic children intended to serve as a manage- }\end{array}$ ment guide and available to all hospital personnel to optimize perioperative patient cooperation and avoid harm. Covered factors including optimal time of day for procedure, modification of hospital arrival time, and avoidance of multiple transitions (Swartz et al., 2017) - Positive (2/2; 100\%)

Outcomes* $(n ; \%)$

- Positive (13/13; 100\%)

- Positive and no clear effects (1/2; 50\%)

- No clear effects $(1 / 1 ; 100 \%)$

- Positive (8/10; $80 \%)$

- Positive and mixed (1/10; $10 \%)$

- Positive and no clear effects $(1 / 10 ; 10 \%)$

- Positive $(2 / 4 ; 50 \%)$

- Positive and no clear effects (2/4; 50\%)

- No clear effects $(1 / 1 ; 100 \%)$

- Positive (1/2; 50\%)

- Positive and no clear effects $(1 / 2 ; 50 \%)$

Positive and no clear effects $(1 / 2 ; 50 \%)$

(1)

Note. QI, quality improvement. *The data resulting from each outcome measure was graded as positive/negative/mixed or no clear effects. Therefore, studies could receive more than one outcome categorization depending on the number of measures used

and there exist a number of tools to facilitate data collection in relation to the barriers to healthcare access experienced by autistic adults (Nicolaidis et al., 2013) or the caregivers of autistic persons (Walsh et al., 2020b) or healthcare providers (Walsh et al., 2021) which should facilitate future research in this area. This research must move beyond developing understanding on, and collecting data relating to experiences of, healthcare access and experiences of autistic persons to "actioning" data to inform the development and implementation of interventions to improve the care and health of autistic persons.

It is notable that interventions were most commonly categorized as patient-focused (58.1\% of studies) and sought to support the autistic individual in engaging with, tolerating, or anticipating medical procedures, care, or settings. All studies using single-subject research designs reported on patientfocused interventions which likely reflects the popularity of the design type in behavior analytic research (Scruggs $\&$ Mastropieri, 1998) and the frequency with which behavior analysts work directly with autistic children and adults (Keenan et al., 2015). It is certainly known that autismrelated characteristics (e.g., sensory issues, communication issues, and challenging behavior) are barriers to healthcare access and may impede the provision of high quality care for autistic patients (Walsh et al., 2020a). However, autistic individuals and caregivers have also highlighted healthcare provider-related barriers (e.g., lack of knowledge/skills and inflexibility) and healthcare system-related barriers (e.g., 
Table 5 Comparison of studies using single-subject research designs and groups research designs

\begin{tabular}{|c|c|c|}
\hline Variable & $\begin{array}{l}\text { Single-subject research designs } \\
(n=10 \text { studies }) \\
n ; \%\end{array}$ & $\begin{array}{l}\text { Groups } \\
\text { research } \\
\text { designs } \\
(n=21 \text { stud- } \\
\text { ies }) \\
n ; \%\end{array}$ \\
\hline \multicolumn{3}{|l|}{ Level of evaluation } \\
\hline Level 1:Reactions & $1 ; 9.1 \%$ & $13 ; 34.2 \%$ \\
\hline Level 2A: Learning: change in attitudes & - & $9 ; 23.7 \%$ \\
\hline Level 2B: Learning: change in knowledge/skill & - & $5 ; 13.2 \%$ \\
\hline Level 3: Behavior & $10 ; 90.9 \%$ & $6 ; 15.8 \%$ \\
\hline $\begin{array}{l}\text { Level 4A: Results: change in system/organizational } \\
\text { practice }\end{array}$ & - & $4 ; 10.5 \%$ \\
\hline Level 4B: Results: change among participants & - & $1 ; 2.6 \%$ \\
\hline \multicolumn{3}{|l|}{ Nature of the intervention } \\
\hline Patient-focused & $10 ; 100 \%$ & $8 ; 32 \%$ \\
\hline Provider-focused & - & $15 ; 60 \%$ \\
\hline Organization-focused & - & $2 ; 8 \%$ \\
\hline \multicolumn{3}{|l|}{ Outcomes } \\
\hline Positive & $11 ; 100 \%$ & $31 ; 81.6 \%$ \\
\hline No clear effects & - & $6 ; 15.8 \%$ \\
\hline Mixed & - & $1 ; 2.6 \%$ \\
\hline \multicolumn{3}{|l|}{ Methodological rigor } \\
\hline Mean QATSDD score & 20.1 & 17.7 \\
\hline Range & $13-28$ & $9-28$ \\
\hline
\end{tabular}

Note. As described in the "Method" section, it was possible for multiple codes to be applied within the same study. Therefore, the numbers presented herein do not align with the total number of included studies lack of continuity/collaboration and lack of time/resources), which were addressed less frequently in included studies ( $48.3 \%$ of studies and $6.5 \%$ of studies, respectively). Future research must look beyond approaches targeting only the behavior of the autistic individual and must instead ensure that interventions target the other factors that are known to impact upon access to, and experiences of, care (Walsh et al., 2020a). Although interventions seeking to change healthcare provider behavior, or management, coordination, or facilities within organizations or healthcare services, may be more complex or resource-intensive, they are essential to ensure that care is improved for the many diverse autistic persons accessing healthcare services daily and addressing unmet needs and issues of poor care which persist in the autistic community (Nicolaidis et al., 2013). Researchers, or quality professionals, may wish to use existing tools to establish the barriers to care in advance of intervention development to ensure that interventions are likely to yield perceptible improvements for autistic patients. For example, Raymaker and colleagues (2017) have developed a tool that allows autistic individuals to self-report barriers experienced in healthcare settings, Walsh et al. (2020b) present a tool which allows the caregivers of autistic patients to report on the frequency and severity of barriers experienced in physical healthcare settings, and Walsh et al. (2021) have completed initial validation of a tool which allows healthcare providers to identify barriers to care provision or access for autistic patients. The use of such tools will allow providers or organizations to determine the most frequent (and in some instances, the most severe) barriers impacting care for autistic patients within their organization or setting. This may allow prioritization and evaluation of interventions or strategies which are likely to address these specific barriers. Walsh and colleagues (Walsh et al., 2020a) have offered recommendations for interventions to address the most common barriers to healthcare access for autistic patients (e.g., the use of picture or visual schedules before and during medical encounters to address communication challenges; use of a shared care plan to facilitate continuity of care or collaboration between healthcare providers). There is additional work required, however, to develop complete and comprehensive guidelines on how to address particular barriers and what interventions might be most appropriate in what instances as this will be crucial to support organizations in implementing effective practices to improve care. Finally, within studies evaluating patient-focused interventions that were intended to change, or teach, behaviors, participants typically received $1: 1$ behavioral interventions in their educational setting which yielded uniformly positive outcomes. There is some research (Law et al., 2018, 2019; Rogerson 
et al., 2019) demonstrating the efficacy of technologies in facilitating the delivery of parent-mediated behavioral intervention to autistic children. Researchers could explore capitalizing on technology to allow such interventions to be accessed more readily by autistic individuals and caregivers or provided more commonly through healthcare services or organizations.

The most important measure of the impact of an intervention to improve access to care and care experiences must be whether it actually improves delivery of care, care experiences, and health outcomes for autistic persons. Included studies typically relied on measures of behavior (54.8\%; Kirkpatrick Level 3) when evaluating intervention outcomes, most commonly the behavior of the autistic individual undergoing a medical procedure, followed by measures of reactions (45.2\%; Kirkpatrick Level 1), typically of healthcare providers to an educational intervention. More than $90 \%$ of studies using single-subject research designs used measures of behavior which, again, likely reflects that these studies were typically behavior analytic in nature and that the measurement of behavior is a cornerstone of applied behavior analysis (Dillenburger \& Keenan, 2009). There was greater variability in outcome measures utilized within studies employing groups designs which likely reflects that these studies have emerged from a variety of disciplines and that a variety of constructs (e.g., knowledge and attitudes) were targeted within the interventions. Notably, less than one-fifth of studies used measures that were classified as Level 4 measures on Kirkpatrick's evaluation hierarchy (Kirkpatrick, 1967). Level 4 measures consider "business results" (Reio et al., 2017) or impact upon the practice of the organization and/or improvements for employees or service-users. Given data on increased morbidity and mortality (Croen et al., 2015; Hirvikoski et al., 2016; Hwang et al., 2019; Mouridsen et al., 2008; Shavelle et al., 2001), unmet healthcare needs (Nicolaidis et al., 2013), and poorer care experiences (Nicolaidis et al., 2013; Tregnago \& Cheak-Zamora, 2012) in autism, we argue that future studies evaluating interventions must assess for stronger indicators of change and impact (e.g., measures of health of autistic persons and measures of patient comfort and/ or distress during healthcare provider consultations). It is crucial also that studies measure what matters to autistic patients (Coulter, 2017). Research which engages the autistic community to determine preferred outcome measures, and/ or which considers what routinely collected healthcare data may offer useful insights, would be of much use in advancing knowledge on how to most efficiently and effectively determine the effect an intervention has had for patients. The measurement of intervention outcomes at the higher Kirkpatrick levels is essential for engaging policymakers and securing financial support (Gordon et al., 2018). Stronger data to support intervention effectiveness may also encourage adoption or uptake of interventions thereby "spreading" positive change in the physical healthcare of persons with autism.

\section{Limitations}

This review had a number of limitations. First, we excluded studies that delivered interventions focused solely on improving screening and/or diagnosis of autism by healthcare professionals and within included studies any related data were not extracted. We recognize that the identification of a patient as autistic may result in better accommodation of the patient's needs and improved healthcare provision. However, these studies are well-reviewed elsewhere (Daniels et al., 2014; McCormack et al., 2019) and were not considered to have the specific focus on improving physical healthcare access or care experiences required.

Second, the focus on interventions to improve physical healthcare access and/or experiences only should be noted. Autistic individuals are at a greater risk for experiencing psychiatric conditions (Croen et al., 2015) so quality of care in mental healthcare services is important. Similarly, autistic individuals may be more likely to experience poor dental or oral health (e.g., caries and receding gums; Blomqvist et al., 2015; Loo et al., 2008). However, as the barriers to physical healthcare access have been delineated (Mason et al., 2019; Walsh et al., 2020a), and may differ from the barriers experiences within other types of services, it was considered most appropriate to focus on interventions that were implemented and evaluated in such settings. Future research that synthesizes data on the barriers to accessing mental, dental, or other forms of healthcare services for autistic individuals, and interventions to address these issues, is recommended.

Finally, the decision to include grey literature within a review can be contentious. There is a lack of established best practice in how to search and engage with grey literature, searches of the grey literature may not be replicable by others, the return on resources invested for identification of grey literature can be limited, and issues with the interpretation or extraction of data within grey literature can arise due to poor methodological quality and/or poor reporting (Benzies et al., 2006; Egger et al., 2003; Mahood et al., 2014; Martin et al., 2005). There is some empirical evidence to suggest that the methodological quality of grey literature studies is poorer than that of peer-reviewed studies (Egger et al., 2003; MacLean et al., 2003). This is an important finding as it suggests the inclusion of grey literature could constitute a threat to the internal validity of a systematic review as it may lack the methodology and controls to address the research question. These are this issues of which a reader should be aware. However, prestigious evidence-synthesis organizations such as Cochrane (Higgins et al., 2019) and 
the Campbell Collaboration (2016) do recommend searches of the grey literature. Within systematic reviews focused on interventions, and their effectiveness, the non-inclusion of grey literature can lead to a problematic overestimation of effect size or overly favorable judgments of intervention effects (Hopewell et al., 2007). Further, grey literature searches are particularly recommended where a small body of research exists, there is a lack of consensus on appropriate outcome measurement, and where the context of the intervention is important (Benzies et al., 2006). Accordingly, we did consider grey literature for inclusion in the current review. Our search tactics were intended to identify grey literature from English-speaking countries through the use of Google (location set to UK; first 100 returns), Google Scholar (location set to UK; first 100 returns), Ethos, and OpenGrey. Specified search locations impact ordering of returns on Google databases. Ethos and OpenGrey are largely focused on grey literature arising from Europe or the UK. Therefore, it is important to note that our grey literature search tactics may not have adequately identified papers published outside of Europe. In total, one grey literature study (Mills, 2017) met our inclusion criteria and has been integrated within the current review to provide as complete as possible of an overview of work to date in this area and to showcase the full extent of interventions which have been trialed in this area. This study was reviewed using the QATSDD, and the quality score achieved (17) was similar to many of the peer-reviewed studies (e.g., mean QATSDD scores for groups designs studies $=17.7$, range 9-28).

\section{Recommendations for Future Research}

The synthesis conducted allows for a number of recommendations for future research to be offered. First, the knowledge, behavior, and attitudes of healthcare providers are a recognized barrier to healthcare access for autistic individuals (Walsh et al., 2020a). However, a majority of provider-focused interventions consisted of educational interventions only, and in most cases, these were largely lecture-based. However, it is well-recognized that the change resulting from education alone is minimal (Soong $\&$ Shojania, 2020). It is essential that future research on educational interventions requires active engagement by participants and affords attendees relevant opportunities to practice target behaviors/knowledge/attitudes and receive feedback if training is to result in changes in behavior that generalize to the clinical environment and into patient consultations. The use of simulation is becoming increasingly commonplace in healthcare research and practice (Walsh et al., 2018) as a means of recreating or replicating patients, clinical situations, and/or facilities. Simulation has the potential to allow physicians to engage in targeted behaviors outside of the clinical setting and to receive corrective feedback which may result in improved clinical performance. Indeed, one included study described the use of an autistic standardized patient (i.e., actor portraying a patient with a particular condition) among nursing students which was reported to impact on communication skills, along with students' critical thinking, prioritization skills, and patient assessment abilities (McIntosh et al., 2015). Simulation could be coupled with in vivo coaching and feedback from an expert to teach healthcare workers how to appropriately perform key non-technical skills (e.g., communication, empathy, and shared decision-making) and technical skills (e.g., physical exams, blood draws, and MRI scans) when caring for autistic patients. Other applications of simulation are possible too. For example, the use of virtual patients to improve knowledge of autism or the use of high-fidelity simulations to explore healthcare workers' implementation of accommodations as outlined in personalized care plans for autistic patients. Future research which further considers the potential for simulation to yield more effective educational interventions is therefore recommended. However, education or training is just one means of improving healthcare delivery and services for autistic patients. Researchers seeking to develop, implement, and evaluate provider-focused interventions should therefore also consider how other forms of provider-focused interventions such as individualized care plans, checklists, guidelines, and technological supports may serve to more effectively improve the experience of autistic patients.

Second, studies scored poorly in the quality assessment in relation to user involvement in the design of the research. Only three studies (Chebuhar et al., 2013; Nicolaidis et al., 2016; Whippey et al., 2019) indicated any involvement of autistic persons or their families in the development of the research or intervention that was reported upon. The rationale for including autistic individuals in the prioritization, planning, and conduct of research relating to autism has been explicated and well-argued (Fletcher-Watson et al., 2019; Jivraj et al., 2014). Although such partnerships may encounter challenges (Pellicano et al., 2014), such involvement will yield data that are more socially valid and may result in improved translation of research and better outcomes for autistic people (Fletcher-Watson et al., 2019). Social validity relates to the importance of intervention targets (i.e., is this an appropriate or useful goal?), the appropriateness of the intervention procedures (i.e., are the intervention procedure acceptable?), and the perceived importance of the outcomes observed (i.e., are stakeholders pleased with the results of the intervention?) (Wolf, 1978), and should be assessed via engagement with stakeholders (i.e., the individual participating within the interventions and those close to them). Social validity has been long discussed in relation to behavioral interventions but its measurement or consideration has not 
been optimal (Schwartz \& Baer, 1991; Wolf, 1978). It is essential that the design of future research, and interventions in this area, is inclusive of autistic individuals, and the caregivers or family members of autistic individuals as appropriate. This will contribute to ensuring that interventions are maximally socially valid and may contribute to clarifying what interventions should be prioritized.

Relatedly, it would be of much use to engage stakeholders (e.g., autistic persons, the caregivers of autistic persons, healthcare providers, and healthcare managers) in a process involving the mapping of barriers to relevant interventions. Researchers have previously attempted to provide suggestions for interventions to address specific barriers to physical healthcare access (e.g., use of picture/ visual schedules as a means of addressing communication difficulties, development, and delivery of training or education to address issues relating to provider knowledge or skills; Walsh et al., 2020a). However, there is a need to complete this process more systematically, to include a comprehensive overview of existing interventions such as that offered in the current review, and to conduct the process in a way that is inclusive of the stakeholders who will be responsible for the delivery of the intervention or who will experience the implementation of the intervention. Intervention mapping approaches such as this are growing in popularity and have been used with patient populations including patients with cancer, patients experiencing mental health issues, patients with HIV, and others (Majid et al., 2018). Such a process may valuably identify frequent or pervasive barriers that are not adequately addressed by existing or previously trialed interventions, may lead to suggestions for novel interventions that could be evaluated, and, through the consideration of the frequency with which specific barriers are reported within research, may assist with the prioritization of interventions for evaluation. There is a clear interest in contributing to the improvement of healthcare services among the autistic community (Warner et al., 2019) so such an exercise may be well received and yield good engagement.

Next, given the relative dearth of literature focused on interventions to improve physical healthcare access, this review has synthesized interventions implemented across all types of healthcare settings. However, it is important to consider differences, or specific challenges or procedures, which may exist across healthcare settings and how these may be addressed. For example, the experience of an autistic patient receiving routine preventative care within a primary care setting from a known family doctor/general practitioner is likely to be quite different to that of an autistic patient admitted to an emergency department while acutely unwell or an autistic patient admitted to hospital for scheduled/ elective surgery. The use of patient narratives is a recognized means of informing quality improvement initiatives in healthcare (Tsianakas et al., 2012; Wilcock et al., 2003) and may be a useful means of furthering understanding of care within specific settings or in relation to specific care services. Alternatively, other qualitative methodologies may usefully elucidate patient experiences. For example, Donovan (2020) describes engagement with autistic women via semi-structured interview in order to develop an understanding of their experiences and particular challenges or difficulties encountered. Nicholas et al. (2016) employed semi-structured interviews to develop an understanding of the experiences of families with an autistic child required to attend the emergency department. As research on the healthcare experiences of individuals with autism increases, such data may usefully facilitate quality improvement in specific services or specialties.

Finally, included studies typically provided limited detail on the implementation of the intervention. This issue of insufficient description of interventions has been identified previously (Glasziou et al., 2010; Michie et al., 2009), has been demonstrated to hinder replication of interventions (Glasziou et al., 2008) by other researchers, and is suggested to contribute substantially to the "waste" of healthcare research (Glasziou et al., 2010) as it precludes the implementation or re-creation of interventions by those working on-the-ground. Further, the effects of interventions which are informed, or delivered, by individuals with high levels of training or expertise, or which are well resourced in terms of personnel or funding, may not be generalizable to other contexts or settings. Therefore, it is essential that future research provides complete detail on intervention content (e.g., components and materials), agent (e.g., expertise/ qualifications and supports provided), setting, delivery of intervention (e.g., frequency and schedule), and any flexibility in delivery of interventions (Glasziou et al., 2010).

\section{Conclusion}

The need to adapt healthcare services for autistic persons is recognized as a priority. However, only a small body of literature internationally has considered how this can be effectively done. Further research is imperative and should look beyond the autistic individual to how provider behavior and healthcare organizations must alter. The design of future research must be inclusive of the autistic community, must measure what matters, and must offer complete detail on interventions implemented.

Supplementary Information The online version contains supplementary material available at https://doi.org/10.1007/s40489-021-00279-2.

Funding Open Access funding provided by the IReL Consortium. Chloe Walsh's doctoral research is funded by the Irish Research Council (Grant number: GOIPG/2017/1356). 


\section{Declarations}

Competing Interests The authors declare no competing interests.

Open Access This article is licensed under a Creative Commons Attribution 4.0 International License, which permits use, sharing, adaptation, distribution and reproduction in any medium or format, as long as you give appropriate credit to the original author(s) and the source, provide a link to the Creative Commons licence, and indicate if changes were made. The images or other third party material in this article are included in the article's Creative Commons licence, unless indicated otherwise in a credit line to the material. If material is not included in the article's Creative Commons licence and your intended use is not permitted by statutory regulation or exceeds the permitted use, you will need to obtain permission directly from the copyright holder. To view a copy of this licence, visit http://creativecommons.org/licenses/by/4.0/.

\section{References}

Ailey, S. H., Brown, P. J., \& Ridge, C. M. (2017). Improving hospital care of patients with intellectual and developmental disabilities. Disability \& Health Journal, 10(2), 169-172. https://doi.org/10. 1016/j.dhjo.2016.12.019

American Psychiatric Association. (2013). Diagnostic and statistical manual of mental disorders (5th ed). https://doi.org/10.1176/ appi.books.9780890425596

Ayres, M., Parr, J. R., Rodgers, J., Mason, D., Avery, L., \& Flynn, D. (2018). A systematic review of quality of life of adults on the autism spectrum. Autism, 22(7), 774-783. https://doi.org/10. $1177 / 1362361317714988$

Barber, C. (2017). Meeting the healthcare needs of adults on the autism spectrum. British Journal of Nursing, 26(7), 420-425. https:// doi.org/10.12968/bjon.2017.26.7.420

Bauer, N. S., Carroll, A. E., Saha, C., \& Downs, S. M. (2015). Computer decision support changes physician practice but not knowledge regarding autism spectrum disorders. Applied Clinical Informatics, 6(3), 454-465. https://doi.org/10.4338/ aci-2014-09-ra-0084

Bellando, J., Fussell, J. J., \& Lopez, M. (2016). Autism speaks toolkits: Resources for busy physicians. Clinical Pediatrics, 55(2), 171-175. https://doi.org/10.1177/0009922815594587

Benzies, K. M., Premji, S., Hayden, K. A., \& Serrett, K. (2006). Stateof-the-evidence reviews: Advantages and challenges of including grey literature. Worldviews on Evidence-Based Nursing, 3(2), 55-61. https://doi.org/10.1111/j.1741-6787.2006.00051.x

Birkan, B., Krantz, P. J., \& McClannahan, L. E. (2011). Teaching children with autism spectrum disorders to cooperate with injections. Research in Autism Spectrum Disorders, 5(2), 941-948. https:// doi.org/10.1016/j.rasd.2010.11.004

Bishop-Fitzpatrick, L., \& Kind, A. J. (2017). A scoping review of health disparities in autism spectrum disorder. Journal of Autism and Developmental Disorders, 47(11), 3380-3391. https://doi. org/10.1007/s10803-017-3251-9

Blomqvist, M., Bejerot, S., \& Dahllöf, G. (2015). A cross-sectional study on oral health and dental care in intellectually able adults with autism spectrum disorder. BMC Oral Health, 15(1), 1-8. https://doi.org/10.1186/s12903-015-0065-Z

Bothwell, L. E., Greene, J. A., Podolsky, S. H., \& Jones, D. S. (2016). Assessing the gold standard-Lessons from the history of RCTs. New England Journal of Medicine, 374(22), 2175-2181.

Broder-Fingert, S., Shui, A., Ferrone, C., Iannuzzi, D., Cheng, E. R., Giauque, A., Connors, S., McDougle, C. J., Donelan, K.,
Neumeyer, A., \& Kuhlthau, K. (2016). A pilot study of autismspecific care plans during hospital admission. Pediatrics, 137, S196-S204. https://doi.org/10.1542/peds.2015-2851R

Brugha, T. S., Spiers, N., Bankart, J., Cooper, S.-A., McManus, S., Scott, F. J., Smith, J., \& Tyrer, F. (2016). Epidemiology of autism in adults across age groups and ability levels. The British Journal of Psychiatry, 209(6), 498-503. https://doi.org/10.1192/bjp.bp. 115.174649

Calleja, S., Islam, F. M. A., Kingsley, J., \& McDonald, R. (2020). Healthcare access for autistic adults: A systematic review. Medicine, 99(29), e20899. https://doi.org/10.1097/MD.0000000000 020899

Carbone, P. S., Norlin, C., \& Young, P. C. (2016). Improving early identification and ongoing care of children with autism spectrum disorder. Pediatrics, 137(6), e20151850. https://doi.org/10.1542/ peds.2015-1850

Carter, J., Broder-Fingert, S., Neumeyer, A., Giauque, A., Kao, A., \& Iyasere, C. (2017). Brief report: Meeting the needs of medically hospitalized adults with autism: A provider and patient toolkit. Journal of Autism and Developmental Disorders, 47(5), 1510 1529. https://doi.org/10.1007/s10803-017-3040-5

Cavalari, R. N., DuBard, M., Luiselli, J. K., \& Birtwell, K. (2013). Teaching an adolescent with autism and intellectual disability to tolerate routine medical examination: Effects of a behavioral compliance training package. Clinical Practice in Pediatric Psychology, 1(2), 121-128. https://doi.org/10.1037/cpp0000013

Chebuhar, A., McCarthy, A. M., Bosch, J., \& Baker, S. (2013). Using picture schedules in medical settings for patients with an autism spectrum disorder. Journal of Pediatric Nursing, 28(2), 125-134. https://doi.org/10.1016/j.pedn.2012.05.004

Clark, A., Browne, S., Boardman, L., Hewitt, L., \& Light, S. (2016). Implementing UK autism policy \& national institute for health and care excellence guidance-assessing the impact of autism training for frontline staff in community learning disabilities teams. British Journal of Learning Disabilities, 44(2), 103-110. https://doi.org/10.1111/bld.12116

Coulter, A. (2017). Measuring what matters to patients. BMJ, 356, j816.

Cox, A. D., Virues-Ortega, J., Julio, F., \& Martin, T. L. (2017). Establishing motion control in children with autism and intellectual disability: Applications for anatomical and functional MRI. Journal of Applied Behavior Analysis, 50(1), 8-26. https://doi.org/ 10.1002/jaba.351

Croen, L. A., Zerbo, O., Qian, Y., Massolo, M. L., Rich, S., Sidney, S., \& Kripke, C. (2015). The health status of adults on the autism spectrum. Autism, 19(7), 814-823. https://doi.org/10.1177/13623 61315577517

Cuvo, A. J., Reagan, A. L., Ackerlund, J., Huckfeldt, R., \& Kelly, C. (2010). Training children with autism spectrum disorders to be compliant with a physical exam. Research in Autism Spectrum Disorders, 4(2), 168-185. https://doi.org/10.1016/j.rasd.2009. 09.001

Daniels, A. M., Halladay, A. K., Shih, A., Elder, L. M., \& Dawson, G. (2014). Approaches to enhancing the early detection of autism spectrum disorders: A systematic review of the literature. Journal of the American Academy of Child \& Adolescent Psychiatry, 53(2), 141-152. https://doi.org/10.1016/j.jaac.2013.11.002

Davit, C. J., Hundley, R. J., Bacic, J. D., \& Hanson, E. M. (2011). A pilot study to improve venipuncture compliance in children and adolescents with autism spectrum disorders. Journal of Developmental and Behavioral Pediatrics, 32(7), 521-525. https://doi. org/10.1097/DBP.0b013e3182245b09

Department of Health (2010). Fulfilling and rewarding lives: The strategy for adults with autism in England. Crown. https://webar chive.nationalarchives.gov.uk/20130104203954/http://www.dh. 
gov.uk/prod_consum_dh/groups/dh_digitalassets/@dh/@en/@ ps/documents/digitalasset/dh_113405.pdf. Accessed July 2021.

Dillenburger, K., \& Keenan, M. (2009). None of the As in ABA stand for autism: Dispelling the myths. Journal of Intellectual and Developmental Disability, 34(2), 193-195. https://doi.org/10. 1080/13668250902845244

Donovan, J. (2020). Childbirth experiences of women with autism spectrum disorder in an acute care setting. Nursing for Women's Health, 24(3), 165-174. https://doi.org/10.1016/j.nwh.2020.04. 001

Drake, J., Johnson, N., Stoneck, A. V., Martinez, D. M., \& Massey, M. (2012). Evaluation of a coping kit for children with challenging behaviors in a pediatric hospital. Pediatric Nursing, 38(4), 215-221.

Edwards, J., \& Northway, R. (2011). Helping a person with autism to overcome her fear of needles. Primary Health Care, 21(10), 26-29. https://doi.org/10.7748/phc2011.12.21.10.26.c8850

Egger, M., Juni, P., Bartlett, C., Holenstein, F., \& Sterne, J. (2003). How important are comprehensive literature searches and the assessment of trial quality in systematic reviews? Empirical study. Health Technololgy Assessment, 7(1), 1-76.

Ellis, E. M., Ala'i-Rosales, S. S., Glenn, S. S., Rosales-Ruiz, J., \& Greenspoon, J. (2006). The effects of graduated exposure, modeling, and contingent social attention on tolerance to skin care products with two children with autism. Research in Developmental Disabilities, 27(6), 585-598. https://doi.org/10.1016/j. ridd.2005.05.009

Emerson, E. (2011). Health status and health risks of the "hidden majority" of adults with intellectual disability. Intellectual and Developmental Disabilities, 49(3), 155-165. https://doi.org/10. 1352/1934-9556-49.3.155

Emerson, E., \& Baines, S. (2011). Health inequalities and people with learning disabilities in the UK. Tizard Learning Disability Review, 16(1), 42-48.

Fletcher-Watson, S., Adams, J., Brook, K., Charman, T., Crane, L., Cusack, J., Leekam, S., Milton, D., Parr, J. R., \& Pellicano, E. (2019). Making the future together: Shaping autism research through meaningful participation. Autism, 23(4), 943-953. https://doi.org/10.1177/1362361318786721

Gernsbacher, M. A. (2017). Editorial perspective: The use of personfirst language in scholarly writing may accentuate stigma. Journal of Child Psychology and Psychiatry, 58(7), 859-861. https:// doi.org/10.1111/jcpp.12706

Ghuman, J. K., Cataldo, M. D., Beck, M. H., \& Slifer, K. J. (2004). Behavioral training for pill-swallowing difficulties in young children with autistic disorder. Journal of Child \& Adolescent Psychopharmacology, 14(4), 601-611. https://doi.org/10.1089/ cap.2004.14.601

Giarelli, E., Ruttenberg, J., \& Segal, A. (2012). Continuing education for nurses in the clinical management of autism spectrum disorders: Results of a pilot evaluation. The Journal of Continuing Education in Nursing, 43(4), 169-176. https://doi.org/10.3928/ 00220124-20111115-01

Gillis, J. M., Hammond Natof, T., Lockshin, S. B., \& Romanczyk, R. G. (2009). Fear of routine physical exams in children with autism spectrum disorders: Prevalence and intervention effectiveness. Focus on Autism and Other Developmental Disabilities, 24(3), 156-168. https://doi.org/10.1177/1088357609338477

Glasziou, P., Chalmers, I., Altman, D. G., Bastian, H., Boutron, I., Brice, A., Jamtvedt, G., Farmer, A., Ghersi, D., \& Groves, T. (2010). Taking healthcare interventions from trial to practice. BMJ, 341, c3852. https://doi.org/10.1136/bmj.c3852

Glasziou, P., Meats, E., Heneghan, C., \& Shepperd, S. (2008). What is missing from descriptions of treatment in trials and reviews? BMJ, 336(7659), 1472-1474. https://doi.org/10.1136/bmj.39590. 732037.47
Golnik, A., Scal, P., Wey, A., \& Gaillard, P. (2012). Autism-specific primary care medical home intervention. Journal of Autism \& Developmental Disorders, 42(6), 1087-1093. https://doi.org/10. 1007/s10803-011-1351-5

Gordon, M., Hill, E., Stojan, J. N., \& Daniel, M. (2018). Educational interventions to improve handover in health care: An updated systematic review. Academic Medicine, 93(8), 1234-1244. https://doi.org/10.1097/ACM.0000000000002236

Graneheim, U. H., \& Lundman, B. (2004). Qualitative content analysis in nursing research: Concepts, procedures and measures to achieve trustworthiness. Nurse Education Today, 24(2), 105-112. https://doi.org/10.1016/j.nedt.2003.10.001

Hammick, M., Dornan, T., \& Steinert, Y. (2010). Conducting a best evidence systematic review. Part 1: From idea to data coding. BEME Guide No. 13. Medical Teacher, 32(1), 3-15. https://doi. org/10.3109/01421590903414245

Hariton, E., \& Locascio, J. J. (2018). Randomised controlled trialsThe gold standard for effectiveness research. British Journal of Obstetrics and Gynaecology, 125(13), 1716.

Havercamp, S. M., Ratliff-Schaub, K., Macho, P. N., Johnson, C. N., Bush, K. L., \& Souders, H. T. (2016). Preparing tomorrow's doctors to care for patients with autism spectrum disorder. Intellectual \& Developmental Disabilities, 54(3), 202-216. https:// doi.org/10.1352/1934-9556-54.3.202

Higgins, J. P., Thomas, J., Chandler, J., Cumpston, M., Li, T., Page, M. J., \& Welch, V. A. (2019). Cochrane handbook for systematic reviews of interventions. Wiley.

Hirvikoski, T., Mittendorfer-Rutz, E., Boman, M., Larsson, H., Lichtenstein, P., \& Bölte, S. (2016). Premature mortality in autism spectrum disorder. The British Journal of Psychiatry, 208(3), 232-238. https://doi.org/10.1192/bjp.bp.114.160192

Hopewell, S., McDonald, S., Clarke, M. J., Egger, M. (2007). Grey literature in meta-analyses of randomized trials of health care interventions. Cochrane Database of Systematic Reviews, (2). https://doi.org/10.1002/14651858.MR000010.pub3

Hwang, Y. I., Srasuebkul, P., Foley, K. R., Arnold, S., \& Trollor, J. N. (2019). Mortality and cause of death of Australians on the autism spectrum. Autism Research, 12(5), 806-815. https://doi. org/10.1002/aur.2086

Iannuzzi, D., Rissmiller, P., Duty, S. M., Feeney, S., Sullivan, M., \& Curtin, C. (2019). Addressing a gap in healthcare access for transition-age youth with autism: A pilot educational intervention for family nurse practitioner students. Journal of Autism \& Developmental Disorders, 49(4), 1493-1504. https://doi.org/10. 1007/s10803-018-3846-9

Jivraj, J., Sacrey, L.-A., Newton, A., Nicholas, D., \& Zwaigenbaum, L. (2014). Assessing the influence of researcher-partner involvement on the process and outcomes of participatory research in autism spectrum disorder and neurodevelopmental disorders: A scoping review. Autism, 18(7), 782-793. https://doi.org/10.1177/ 1362361314539858

Kamat, P. P., Bryan, L. N., McCracken, C. E., Simon, H. K., Berkenbosch, J. W., \& Grunwell, J. R. (2018). Procedural sedation in children with autism spectrum disorders: A survey of current practice patterns of the society for pediatric sedation members. Pediatric Anesthesia, 28(6), 552-557. https://doi.org/10.1111/ pan. 13387

Keenan, M., Dillenburger, K., Röttgers, H. R., Dounavi, K., Jónsdóttir, S. L., Moderato, P., Schenk, J. J., Virués-Ortega, J., RollPettersson, L., \& Martin, N. (2015). Autism and ABA: The gulf between North America and Europe. Review Journal of Autism and Developmental Disorders, 2(2), 167-183. https://doi.org/10. 1007/s40489-014-0045-2

Kenny, L., Hattersley, C., Molins, B., Buckley, C., Povey, C., \& Pellicano, E. (2016). Which terms should be used to describe autism? 
Perspectives from the UK autism community. Autism, 20(4), 442-462. https://doi.org/10.1177/1362361315588200

Khanna, R., Jariwala-Parikh, K., West-Strum, D., \& Mahabaleshwarkar, R. (2014). Health-related quality of life and its determinants among adults with autism. Research in Autism Spectrum Disorders, 8(3), 157-167. https://doi.org/10.1016/j.rasd.2013. 11.003

Kirkpatrick, D. L. (1967). Evaluation of training. In R. L. Craig \& L. R. Bittel (Eds.), Training and development handbook (pp. 87-112). McGraw Hill.

Koski, S., Gabriels, R. L., \& Beresford, C. (2016). Interventions for paediatric surgery patients with comorbid autism spectrum disorder: A systematic literature review. Archives of Disease in Childhood, 101(12), 1090-1094. https://doi.org/10.1136/archd ischild-2016-310814

Kuhlthau, K., Orlich, F., Hall, T. A., Sikora, D., Kovacs, E. A., Delahaye, J., \& Clemons, T. E. (2010). Health-related quality of life in children with autism spectrum disorders: Results from the autism treatment network. Journal of Autism and Developmental Disorders, 40(6), 721-729. https://doi.org/10.1007/ s10803-009-0921-2

Kupzyk, S., \& Allen, K. D. (2019). A review of strategies to increase comfort and compliance with medical/dental routines in persons with intellectual and developmental disabilities. Journal of Developmental and Physical Disabilities, 31(2), 231-249. https://doi.org/10.1007/s10882-018-09656-y

Kuriakose, S., Filton, B., Marr, M., Okparaeke, E., Cervantes, P., Siegel, M., Horwitz, S., \& Havens, J. (2018). Does an autism spectrum disorder care pathway improve care for children and adolescents with ASD in inpatient psychiatric units? Journal of Autism \& Developmental Disorders, 48(12), 4082-4089. https:// doi.org/10.1007/s10803-018-3666-y

Law, G. C., Dutt, A., \& Neihart, M. (2019). Increasing intervention fidelity among special education teachers for autism intervention: A pilot study of utilizing a mobile-app-enabled training program. Research in Autism Spectrum Disorders, 67, 101411. https://doi. org/10.1016/j.rasd.2019.101411

Law, G. C., Neihart, M., \& Dutt, A. (2018). The use of behavior modeling training in a mobile app parent training program to improve functional communication of young children with autism spectrum disorder. Autism, 22(4), 424-439. https://doi.org/10.1177/ 1362361316683887

Loo, C. Y., Graham, R. M., \& Hughes, C. V. (2008). The caries experience and behavior of dental patients with autism spectrum disorder. The Journal of the American Dental Association, 139(11), 1518-1524. https://doi.org/10.14219/jada.archive.2008.0078

Lucarelli, J., Welchons, L., Sideridis, G., Sullivan, N. R., Chan, E., \& Weissman, L. (2018). Development and evaluation of an educational initiative to improve hospital personnel preparedness to care for children with autism spectrum disorder. Journal of Developmental and Behavioral Pediatrics, 39(5), 358-364. https://doi.org/10.1097/DBP.0000000000000580

Lydon, S., Healy, O., O'Callaghan, O., Mulhern, T., \& Holloway, J. (2015). A systematic review of the treatment of fears and phobias among children with autism spectrum disorders. Review Journal of Autism and Developmental Disorders, 2(2), 141-154. https:// doi.org/10.1007/s40489-014-0043-4

MacLean, C. H., Morton, S. C., Ofman, J. J., Roth, E. A., \& Shekelle, P. G. (2003). How useful are unpublished data from the Food and Drug Administration in meta-analysis? Journal of Clinical Epidemiology, 56(1), 44-51. https://doi.org/10.1016/s08954356(02)00520-6

Mahood, Q., Van Eerd, D., \& Irvin, E. (2014). Searching for grey literature for systematic reviews: Challenges and benefits. Research Synthesis Methods, 5(3), 221-234. https://doi.org/10.1002/jrsm. 1106
Majid, U., Kim, C., Cako, A., \& Gagliardi, A. R. (2018). Engaging stakeholders in the co-development of programs or interventions using intervention mapping: A scoping review. PLOS ONE, 13(12), e0209826. https://doi.org/10.1371/journal.pone.0209826

Martin, J. L. R., Pérez, V., Sacristán, M., \& Álvarez, E. (2005). Is grey literature essential for a better control of publication bias in psychiatry? An example from three meta-analyses of schizophrenia. European Psychiatry, 20(8), 550-553. https://doi.org/10.1016/j. eurpsy.2005.03.011

Mason, D., Ingham, B., Urbanowicz, A., Michael, C., Birtles, H., Woodbury-Smith, M., Brown, T., James, I., Scarlett, C., \& Nicolaidis, C. (2019). A systematic review of what barriers and facilitators prevent and enable physical healthcare services access for autistic adults. Journal of Autism and Developmental Disorders, 49(8), 3387-3400. https://doi.org/10.1007/s10803-019-04049-2

Mazurek, M. O., Brown, R., Curran, A., \& Sohl, K. (2017). ECHO autism. Clinical Pediatrics, 56(3), 247-256. https://doi.org/10. $1177 / 0009922816648288$

Mazurek, M. O., Curran, A., Burnette, C., \& Sohl, K. (2019). ECHO autism STAT: Accelerating early access to autism diagnosis. Journal of Autism \& Developmental Disorders, 49(1), 127-137. https://doi.org/10.1007/s10803-018-3696-5

McCormack, G., Dillon, A. C., Healy, O., Walsh, C., \& Lydon, S. (2019). Primary care physicians' knowledge of autism and evidence-based interventions for autism: A systematic review. Review Journal of Autism and Developmental Disorders, 7, 226-241. https://doi.org/10.1007/s40489-019-00189-4

McGonigle, J., Migyanka, J., Glor-Scheib, S., Cramer, R., Fratangeli, J., Hegde, G., Shang, J., \& Venkat, A. (2014). Development and evaluation of educational materials for pre-hospital and emergency department personnel on the care of patients with autism spectrum disorder. Journal of Autism \& Developmental Disorders, 44(5), 1252-1259. https://doi.org/10.1007/ s10803-013-1962-0

McIntosh, C. E., Thomas, C. M., Allen, R. A., \& Edwards, J. A. (2015). Using a combination of teaching and learning strategies and standardized patient for a successful autism simulation. Clinical Simulation in Nursing, 11(3), 143-152. https://doi.org/10.1016/j. ecns.2014.11.008

Michie, S., Jochelson, K., Markham, W. A., \& Bridle, C. (2009). Lowincome groups and behaviour change interventions: A review of intervention content, effectiveness and theoretical frameworks. Journal of Epidemiology \& Community Health, 63(8), 610-622.

Mills, H. (2017). Evaluating the use of the 'show me where' picture communication system when conducting medical examinations on children with autistic spectrum disorder [Unpublished doctoral dissertation]. University of Cardiff.

Moher, D., Liberati, A., Tetzlaff, J., Altman, D. G., \& Group, P. (2009). Preferred reporting items for systematic reviews and meta-analyses: The PRISMA statement. PLoS Medicine, 6(7), e1000097. https://doi.org/10.1371/journal.pmed.1000097

Mouridsen, S. E., Brønnum-Hansen, H., Rich, B., \& Isager, T. (2008). Mortality and causes of death in autism spectrum disorders: An update. Autism, 12(4), 403-414. https://doi.org/10. $1177 / 1362361308091653$

Muskat, B., Burnham Riosa, P., Nicholas, D. B., Roberts, W., Stoddart, K. P., \& Zwaigenbaum, L. (2015). Autism comes to the hospital: The experiences of patients with autism spectrum disorder, their parents and health-care providers at two Canadian paediatric hospitals. Autism, 19(4), 482-490. https://doi. org/10.1177/1362361314531341

Nguyền, A. (2009). Environment and surroundings: How to make them autism-friendly. National Autistic Society.

Nicholas, D. B., Zwaigenbaum, L., Muskat, B., Craig, W. R., Newton, A. S., Kilmer, C., Greenblatt, A., Roberts, W., \& CohenSilver, J. (2016). Experiences of emergency department care 
from the perspective of families in which a child has autism spectrum disorder. Social Work in Health Care, 55(6), 409426. https://doi.org/10.1080/00981389.2016.1178679

Nicolaidis, C., Kripke, C. C., \& Raymaker, D. (2014). Primary care for adults on the autism spectrum. Medical Clinics of North America, 98(5), 1169-1191. https://doi.org/10.1016/j.mcna. 2014.06.011

Nicolaidis, C., Raymaker, D., McDonald, K., Dern, S., Boisclair, W. C., Ashkenazy, E., \& Baggs, A. (2013). Comparison of healthcare experiences in autistic and non-autistic adults: A cross-sectional online survey facilitated by an academiccommunity partnership. Journal of General Internal Medicine, 28(6), 761-769. https://doi.org/10.1007/s11606-012-2262-7

Nicolaidis, C., Raymaker, D., McDonald, K., Kapp, S., Weiner, M., Ashkenazy, E., Gerrity, M., Kripke, C., Platt, L., \& Baggs, A. (2016). The development and evaluation of an online healthcare toolkit for autistic adults and their primary care providers. Journal of General Internal Medicine, 31(10), 1180-1189. https://doi.org/10.1007/s11606-016-3763-6

O'Dea, A., O'Connor, P., \& Keogh, I. (2014). A meta-analysis of the effectiveness of crew resource management training in acute care domains. Postgraduate Medical Journal, 90(1070), 699-708. https://doi.org/10.1136/postgradmedj-2014-132800

O’Dowd, E., Lydon, S., O'Connor, P., Madden, C., \& Byrne, D. (2019). A systematic review of 7 years of research on entrustable professional activities in graduate medical education, 2011-2018. Medical Education, 53(3), 234-249. https://doi. org/10.1111/medu.13792

Pellicano, E., Dinsmore, A., \& Charman, T. (2014). Views on researcher-community engagement in autism research in the United Kingdom: A mixed-methods study. PLoS ONE, 9(10), e109946. https://doi.org/10.1371/journal.pone.0109946

Raymaker, D. M., McDonald, K. E., Ashkenazy, E., Gerrity, M., Baggs, A. M., Kripke, C., ... \& Nicolaidis, C. (2017). Barriers to healthcare: Instrument development and comparison between autistic adults and adults with and without other disabilities. Autism, 21(8), 972-984.

Reio, T. G., Rocco, T. S., Smith, D. H., \& Chang, E. (2017). A critique of Kirkpatrick's evaluation model. New Horizons in Adult Education and Human Resource Development, 29(2), 35-53. https:// doi.org/10.1002/nha3.20178

Riosa, P. B., Greenblatt, A., \& Muskat, B. (2017). An online ASD learning module for pediatric health care professionals. Advances in Autism, 3(3), 154-162. https://doi.org/10.1108/ aia-03-2017-0007

Riviere, V., Becquet, M., Peltret, E., Facon, B., \& Darcheville, J. C. (2011). Increasing compliance with medical examination requests directed to children with autism: Effects of a high-probability request procedure. Journal of Applied Behavior Analysis, 44(1), 193-197. https://doi.org/10.1901/jaba.2011.44-193

Robison, J. E. (2019). Talking about autism-Thoughts for researchers. Autism Research, 12(7), 1004-1006. https://doi.org/10.1002/ aur.2119

Rogerson, J., Falkmer, M., Cuomo, B., Falkmer, T., Whitehouse, A. J. O., Granich, J., \& Vaz, S. (2019). Parental experiences using the Therapy Outcomes by You (TOBY) application to deliver early intervention to their child with autism. Developmental Neurorehabilitation, 22(4), 219-227. https://doi.org/10.1080/17518423. 2018.1440259

Rydzewska, E., Hughes-McCormack, L. A., Gillberg, C., Henderson, A., MacIntyre, C., Rintoul, J., \& Cooper, S.-A. (2019). General health of adults with autism spectrum disorders-A whole country population cross-sectional study. Research in Autism Spectrum Disorders, 60, 59-66. https://doi.org/10.1016/j.rasd. 2019.01.004
Sandelowski, M., Voils, C. I., Leeman, J., \& Crandell, J. L. (2012). Mapping the mixed methods-mixed research synthesis terrain. Journal of Mixed Methods Research, 6(4), 317-331. https://doi. org/10.1177/1558689811427913

Schiff, A., Tarbox, J., Lanagan, T., \& Farag, P. (2011). Establishing compliance with liquid medication administration in a child with autism. Journal of Applied Behavior Analysis, 44(2), 381-385. https://doi.org/10.1901/jaba.2011.44-381

Schwartz, I. S., \& Baer, D. M. (1991). Social validity assessments: Is current practice state of the art? Journal of Applied Behavior Analysis, 24(2), 189-204. https://doi.org/10.1901/jaba.1991.24-189

Scott, M., \& Rawal, S. (2018). The promise of equity: A review of health equity research in high-impact quality improvement journals. American Journal of Medical Quality, 33(3), 269-273. https://doi.org/10.1177/1062860617726854

Scruggs, T. E., \& Mastropieri, M. A. (1998). Summarizing singlesubject research: Issues and applications. Behavior Modification, 22(3), 221-242. https://doi.org/10.1177/01454455980223001

Shabani, D. B., \& Fisher, W. W. (2006). Stimulus fading and differential reinforcement for the treatment of needle phobia in a youth with autism. Journal of Applied Behavior Analysis, 39(4), 449452. https://doi.org/10.1901/jaba.2006.30-05

Shakes, P., \& Cashin, A. (2019). Identifying language for people on the autism spectrum: A scoping review. Issues in Mental Health Nursing, 40(4), 317-325. https://doi.org/10.1080/01612840. 2018.1522400

Shavelle, R. M., Strauss, D. J., \& Pickett, J. (2001). Causes of death in autism. Journal of Autism and Developmental Disorders, 31(6), 569-576. https://doi.org/10.1023/A:1013247011483

Sirriyeh, R., Lawton, R., Gardner, P., \& Armitage, G. (2012). Reviewing studies with diverse designs: The development and evaluation of a new tool. Journal of Evaluation in Clinical Practice, 18(4), 746-752. https://doi.org/10.1111/j.1365-2753.2011.01662.x

Soong, C., \& Shojania, K. G. (2020). Education as a low-value improvement intervention: Often necessary but rarely sufficient. BMJ Quality and Safety, 29, 353-357.

Souders, M. C., Freeman, K. G., DePaul, D., \& Levy, S. E. (2002). Caring for children and adolescents with autism who require challenging procedures. Pediatric Nursing, 28(6), 555-583.

Swartz, J. S., Amos, K. E., Brindas, M., Girling, L. G., \& Ruth Graham, M. (2017). Benefits of an individualized perioperative plan for children with autism spectrum disorder. Pediatric Anesthesia, 27(8), 856-862. https://doi.org/10.1111/pan.13189

The Methods Group of the Campbell Collaboration (2016). Methodological expectations of Campbell Collaboration intervention reviews: Conduct standards. Campbell Policies and Guidelines Series, 3. https://doi.org/10.4073/cpg.2016.3

Tregnago, M. K., \& Cheak-Zamora, N. C. (2012). Systematic review of disparities in health care for individuals with autism spectrum disorders in the United States. Research in Autism Spectrum Disorders, 6(3), 1023-1031. https://doi.org/10.1016/j.rasd.2012.01. 005

Tsianakas, V., Maben, J., Wiseman, T., Robert, G., Richardson, A., Madden, P., Griffin, M., \& Davies, E. A. (2012). Using patients' experiences to identify priorities for quality improvement in breast cancer care: Patient narratives, surveys or both? BMC Health Services Research, 12(1), 271. https://doi.org/10.1186/ 1472-6963-12-271

Venkat, A., Jauch, E., Russell, W. S., Crist, C. R., \& Farrell, R. (2012). Care of the patient with an autism spectrum disorder by the general physician. Postgraduate Medical Journal, 88(1042), 472481. https://doi.org/10.1136/postgradmedj-2011-130727

Walsh, C., Lydon, S., Byrne, D., Madden, C., Fox, S., \& O'Connor, P. (2018). The 100 most cited articles on healthcare simulation: A bibliometric review. Simulation in Healthcare, 13(3), 211-220. https://doi.org/10.1097/SIH.0000000000000293 
Walsh, C., Lydon, S., O’Dowd, E., \& O'Connor, P. (2020a). Barriers to healthcare for persons with autism: A systematic review of the literature and development of a taxonomy. Developmental Neurorehabilitation, 23, 413-430. https://doi.org/10.1080/17518 423.2020.1716868

Walsh, C., Lydon, S., Geoghegan, R., Carey, C., Creed, M., O'Loughlin, L., Walsh, E., Byrne, D., O'Connor, P. (2021). Development and preliminary evaluation of a novel physicianreport tool for assessing barriers to providing care to autistic patients. Manuscript under review.

Walsh, C., Lydon, S., Hehir, A., \& O'Connor, P. (2020b). Development and evaluation of a novel caregiver-report tool to assess barriers to physical healthcare for persons on the autism spectrum. Research in Autism Spectrum Disorders, 79, 101680. https://doi. org/10.1016/j.rasd.2020.101680

Warner, G., Parr, J. R., \& Cusack, J. (2019). Workshop report: Establishing priority research areas to improve the physical health and well-being of autistic adults and older people. Autism in Adulthood, 1(1), 20-26. https://doi.org/10.1089/aut.2018.0003

Whippey, A., Bernstein, L. M., O'Rourke, D., \& Reddy, D. (2019). Enhanced perioperative management of children with autism: A pilot study. Canadian Journal of Anesthesia-Journal Canadien D Anesthesie, 66(10), 1184-1193. https://doi.org/10.1007/ s12630-019-01410-y
Whitehead, M. (1991). The concepts and principles of equity and health. Health Promotion International, 6(3), 217-228. https:// doi.org/10.2190/986L-LHQ6-2VTE-YRRN

Wilcock, P. M., Stewart Brown, G. C., Bateson, J., Carver, J., \& Machin, S. (2003). Using patient stories to inspire quality improvement within the NHS Modernization Agency collaborative programmes. Journal of Clinical Nursing, 12(3), 422-430. https://doi.org/10.1046/j.1365-2702.2003.00780.x

Wolf, M. M. (1978). Social validity: The case for subjective measurement or how applied behavior analysis is finding its heart. Journal of Applied Behavior Analysis, 11(2), 203-214. https:// doi.org/10.1901/jaba.1978.11-203

Wolff, J. J., \& Symons, F. J. (2013). An evaluation of multi-component exposure treatment of needle phobia in an adult with autism and intellectual disability. Journal of Applied Research in Intellectual Disabilities, 26(4), 344-348. https://doi.org/10.1111/jar.12002

Publisher's Note Springer Nature remains neutral with regard to jurisdictional claims in published maps and institutional affiliations. 